\title{
Microstructure and Properties of 7075Al Alloy Fabricated by Directly Combined of Spray Forming and Continuous Extrusion Forming under Different Atomization Gas Pressures
}

\author{
Ye-Gao Chen ${ }^{1} \cdot$ Yi Zhong ${ }^{1} \cdot$ Jiang-Cheng Yin ${ }^{1} \cdot$ Li-Qiang Wang $^{1} \cdot$ Li-Na Liu $^{1} \cdot$ Huan Yang $^{1} \cdot$ Ying-Li Liu $^{1}$
}

Received: 7 March 2016/Revised: 10 May 2016/Published online: 28 June 2016

(C) The Chinese Society for Metals and Springer-Verlag Berlin Heidelberg 2016

\begin{abstract}
A new process consisting of the spray forming and the continuous extrusion forming for manufacturing 7075Al alloy was proposed. The microstructure evolution, mechanical properties and the resistance to stress corrosion cracking of the alloy were studied. The results indicate that the spray forming process induces obviously grain refinement and greatly lower segregation microstructure. Besides, the Conform process produces finer grains and conduces to more uniform distribution of the precipitates of $\mathrm{AlCu}$ and $\mathrm{MgZn}_{2}$ phases. The fabricated alloy shows good comprehensive mechanical properties and superb performance of stress corrosion resistance. Moreover, a better combination of the mechanical properties and the resistance to stress corrosion cracking could then be obtained under a certain condition of atomization gas pressure of $0.19 \mathrm{MPa}$. The enhanced properties are attributed to the following factors, which include the grain refinement, the fine and homogeneous distribution of $\mathrm{AlCu}$ and $\mathrm{MgZn}_{2}$ phases, the high density of the extruded products, as well as the discontinuous distribution of the grain boundaries after retrogression and reaging (RRA) heat treatment.
\end{abstract}

KEY WORDS: 7075Al alloy; Spray forming; Continuous extrusion forming; Microstructure; Property

\section{Introduction}

With the development of social economics, the need for more economical processing method for manufacturing high property 7075 aluminum alloy has become more and more urgent [1]. 7075Al alloy, one of the 7000 series alloys, is extensively used in the aerospace and automobile industries due to its high strength, low density and good workability. It is well known that the high strength aluminum alloy is, in most cases, associated with fine-scale precipitation of the metastable $\mathrm{Zn}$ - and $\mathrm{Mg}$-rich phases and GP zones [2-11].

Available online at http://link.springer.com/journal/40195

Yi Zhong

zy5125990@163.com

1 Faculty of Materials Science and Engineering, Kunming University of Science and Technology, Kunming 650000, China
Spray forming, first proposed by Singer in the 1970s [12], is a relatively novel technology for manufacturing near-net-shaped metallic products with enhanced material properties and performance. Due to the rapid solidification of the gas-atomized molten droplets during the flight and deposition procedure, the products fabricated by spraying forming are therefore characterized by fine, uniform and macro-segregation-free microstructure. Besides, the spray forming has been widely used to prepare high alloy materials, such as hypereutectic aluminum silicon alloys [15-17], Al-Zn-Mg-Cu alloys [1, 2, 8, 18-21]. In addition, the oxidation can be significantly reduced under a protective atmosphere during the spray forming process. Therefore, the spray forming is an appropriate and suitable process for manufacturing aluminum alloys.

The continuous extrusion forming process invented by Green in 1971 [22] has been broadly used in the efficient continuous production of aluminum alloys due to its irreplaceable advantages of energy saving, near-net-shape forming, high extrusion ratio and production efficiency, 
fine microstructure, large length, as well as high homogeneity [23]. During the Conform process, the feed stock suffers severe shear deformation when passing the abutment and the extrusion cavity. So the material was subjected to high temperature and pressure. Then, it was extruded out through an extrusion die to form eventually. The products produced by Conform mainly include tubes, solids, complex profiles and coaxial products [24, 25].

Based on the previous works, a novel method for manufacturing $7075 \mathrm{Al}$ alloy including the spray forming process and the Conform process was proposed [26-28]. Figure 1 shows the principle schematic diagram of the new method. Furthermore, the microstructure evolution, mechanical properties and the resistance to stress corrosion cracking of the fabricated products were studied.

\section{Experimental}

Experiment was performed on commercial $7075 \mathrm{Al}$ alloy. The steps were as follows: Firstly, $7075 \mathrm{Al}$ alloy was superheated to about $100{ }^{\circ} \mathrm{C}$ in a box resistor-stove and then it was transferred into an atomizer, which was constructed above the extrusion wheel. The distance between the exit of the nozzle and the surface of the wheel was $250 \mathrm{~mm}$. The inner diameter of the nozzle installed in the atomizer was $3 \mathrm{~mm}$, and the diameter would remain unchanged during the experiment. The melted $7075 \mathrm{Al}$

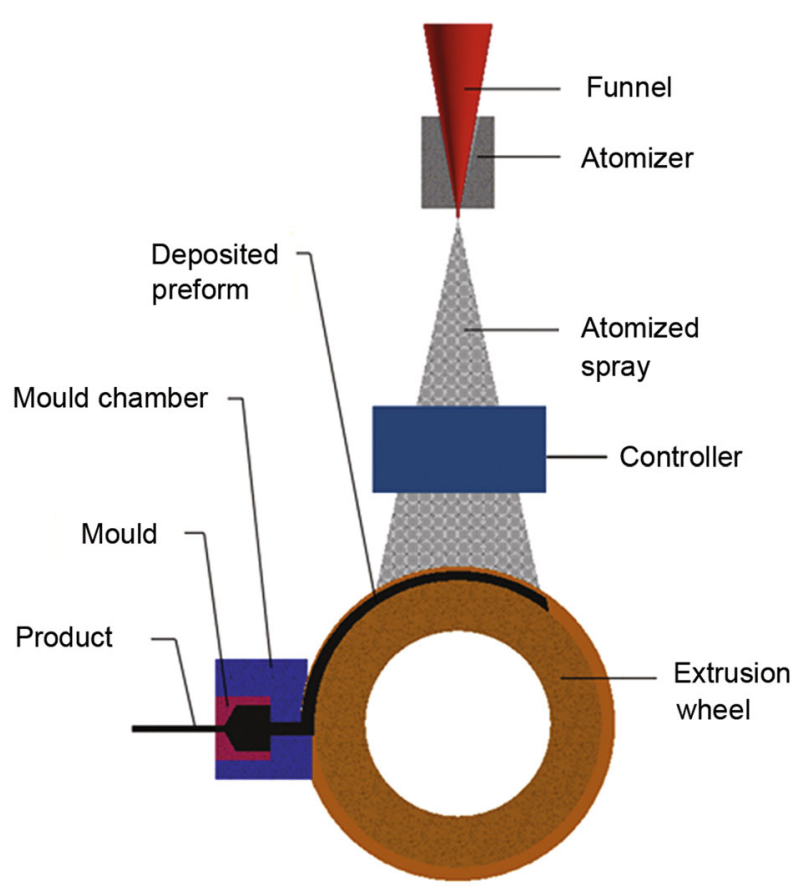

Fig. 1 Schematic diagram of the process of directly combined of the spray forming and the continuous extrusion forming alloy was atomized by $\mathrm{N}_{2}$ under different gas pressures of $0.15,0.17,0.19$ and $0.21 \mathrm{MPa}$, respectively. The atomized droplets were sprayed into the groove of the extrusion wheel vertically under the action of the controller. And the extrusion wheel with a diameter of $340 \mathrm{~mm}$ acted as the substrate. The wheel revolving speed was $4 \mathrm{rpm}$, and the preheating temperature of the die was about $380{ }^{\circ} \mathrm{C}$.

The $7075 \mathrm{Al}$ alloy was produced under different atomization gas pressures, and to obtain a better combination of the mechanical properties and resistance to stress cracking, the alloy was heat-treated to the RRA condition. The following recipes were used: solution-treated $\left(450{ }^{\circ} \mathrm{C}\right.$, $\left.1 \mathrm{~h}+475{ }^{\circ} \mathrm{C}, 2 \mathrm{~h}\right) \rightarrow$ water-quenched $\rightarrow$ aged $\left(120^{\circ} \mathrm{C}\right.$, $24 \mathrm{~h}) \rightarrow$ high-temperature-aged $\left(200^{\circ} \mathrm{C}, 10 \mathrm{~min}\right) \rightarrow$ aged $\left(120{ }^{\circ} \mathrm{C}, 24 \mathrm{~h}\right)$.

The microstructure evolution was researched using an XJP-6A optical microscope (OM), a XL30-ESEMTMP scanning electron microscope (SEM) and a Tecnai G2 TF30 transmission electron microscope (TEM). Keller's etchant was applied to show the grain structure and the highlight precipitates. The X-ray diffraction (XRD) patterns were recorded by the Rigaku D/max 2200 diffractometer system with $\mathrm{Cu} K_{\alpha}$ radiation. The tensile tests were conducted on an AG-X100KN screw-driven test machine at a constant strain rate of $0.5 \mathrm{~mm} / \mathrm{min}$. SEM was used to study the fractographic features of the tensile samples. The electric conductivity was measured using a LSR-3 Seebeck Linseis instrument.

\section{Results and Discussion}

\subsection{Microstructure of the Spray-Deposited Preform}

Figure 2 shows the initial microstructure of the spray-deposited preform of the 7075Al alloy under different atomization gas pressures while maintaining other parameters unchanged. It is obvious that the equiaxed grains with a diameter of $10-50 \mu \mathrm{m}$ and numerous porosities are observed $[29,30]$. And the differences of the grain size and the amount of porosities are associated with the atomization gas pressures during spraying. With rapid solidification rate, low macro-segregation and inconspicuous precipitates would be found both in the matrix and at the grain boundaries.

Apparently, along with the increase of the gas pressures, almost all the grain size decreases and then increases slightly. However, the porosity increases noticeably, as shown in Fig. 3. The reason why the packing density is generally at a low level is that the groove rotates ceaselessly during the process, which leads to the spray cannot deposit continuously on the substrate. In addition, the packing density decreases gradually owing to the increase 

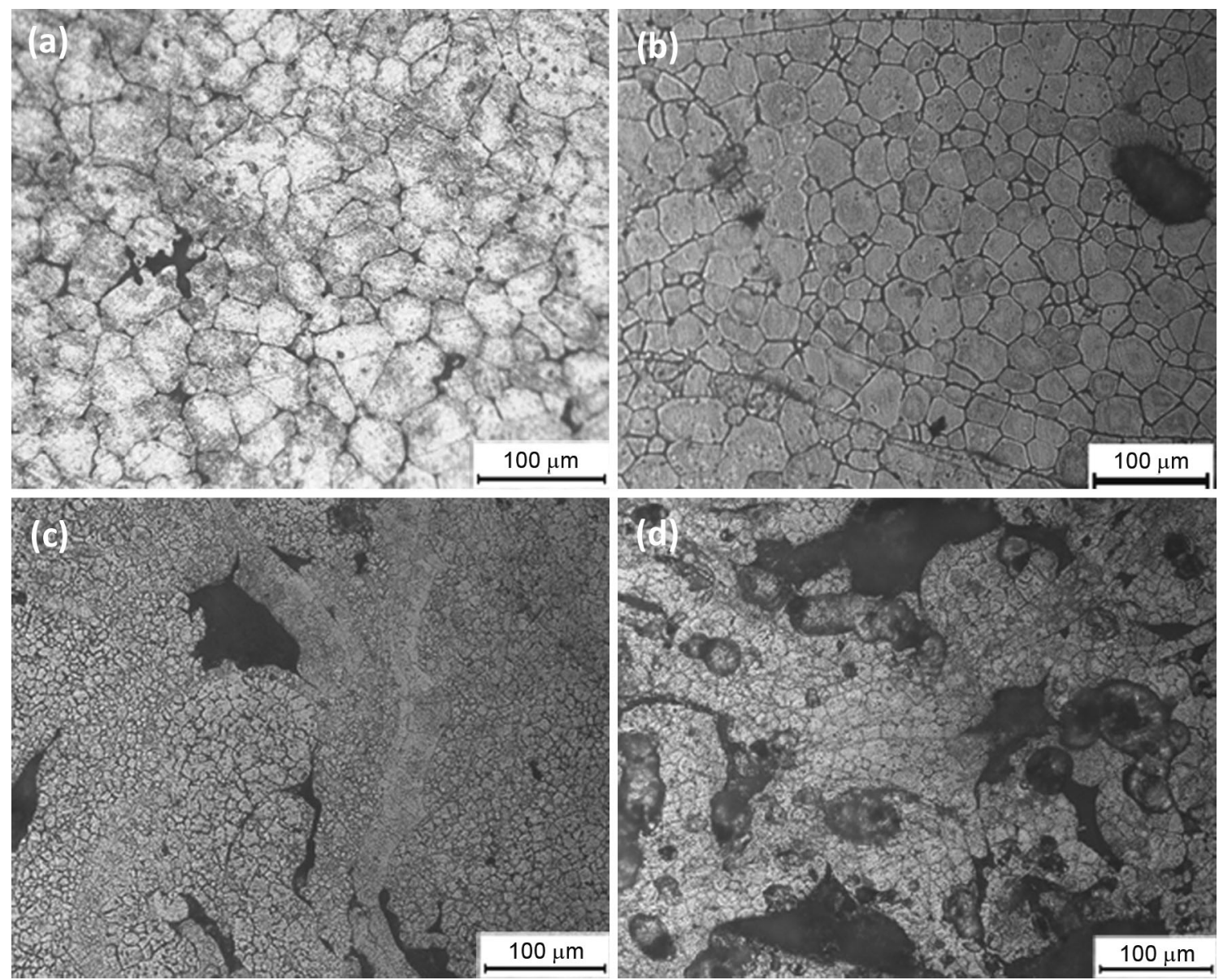

Fig. 2 Optical micrographs of the spray-deposited preform of the $7075 \mathrm{Al}$ alloy under different atomization gas pressures: a $0.15 \mathrm{MPa}$; b $0.17 \mathrm{MPa}$; c $0.19 \mathrm{MPa}$; $0.21 \mathrm{MPa}$

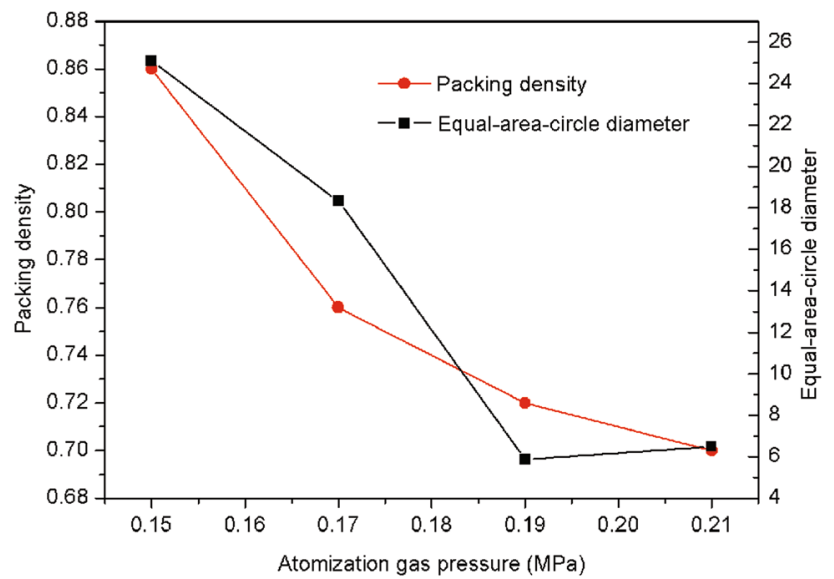

Fig. 3 Variations of the packing density and the grain size with the atomization gas pressures

of the cooling intensity, which was determined by the atomization gas pressure. Once the solid fraction is too high, there would have no sufficient liquid to supplement the porosity. In the case, the porosity would thus exist in the deposited material and lead to low packing density.

The grain size basically becomes smaller with the increase of the atomizing gas pressure, and the reasons are as follows. On the one hand, more heat was removed from the spray droplets through higher gas pressure. On the other hand, the droplets, which are atomized under higher gas pressure, own bigger impulse when impinging on the substrate [31]. A faster cooling rate could be obtained with more heat taken away from the spray, which would contribute to the increase of the driving force for the nucleation in each single droplet. Higher driving force for nucleation results in more incipient crystals meeting the conditions for growing up. Therefore, smaller grains would be got if the atomization gas pressure is higher. Furthermore, the sharp impingement would break dendrite easily, especially when droplets have large impulse. The dropped arms act as the cores of the nucleation of the new grains. As a result, the amount of nucleus is greatly boomed and thus results in more grains generated in a constant region. That is to say, the finer grains could be obtained by 
controlling the gas pressures. However, the grain size at $0.21 \mathrm{MPa}$ is slightly larger than that at $0.19 \mathrm{MPa}$, which is probably related to the area of the deposited material, the temperature of the substrate, the flow rate of the melted material and so on [32].

\subsection{Microstructure of the Processed 7075Al Alloy}

The TEM microstructures of the transverse section of the processed $7075 \mathrm{Al}$ alloy obtained at different spraying gas pressures are shown in Fig. 4. There are some obvious changes of the grains and porosity morphologies compared with those of the as-deposited materials (Fig. 2). A more homogeneous distribution of the finer grains can be found in the extruded alloy. And the grain size reduces to the level of $1-2 \mu \mathrm{m}$ with the increase of the atomization gas pressure. For example, the average grain size would decrease from about 2 (Fig. 4a) to $1 \mu \mathrm{m}$ (Fig. 4d) as atomization gas pressure increases from 0.15 (Fig. 4a) to $0.21 \mathrm{MPa}$ (Fig. 4d) with the other parameters remain unchanged. The degree of segregation of the extruded material is basically identical to the as-sprayed preform. Small amounts of fine precipitates, however, were found both in the grains and at the grain boundaries, which are related to the deformation and the temperature of the metal during the whole process $[13,14,33]$. Segregation-free billets prepared by the spray forming would certainly contribute to the segregation-free products. In the
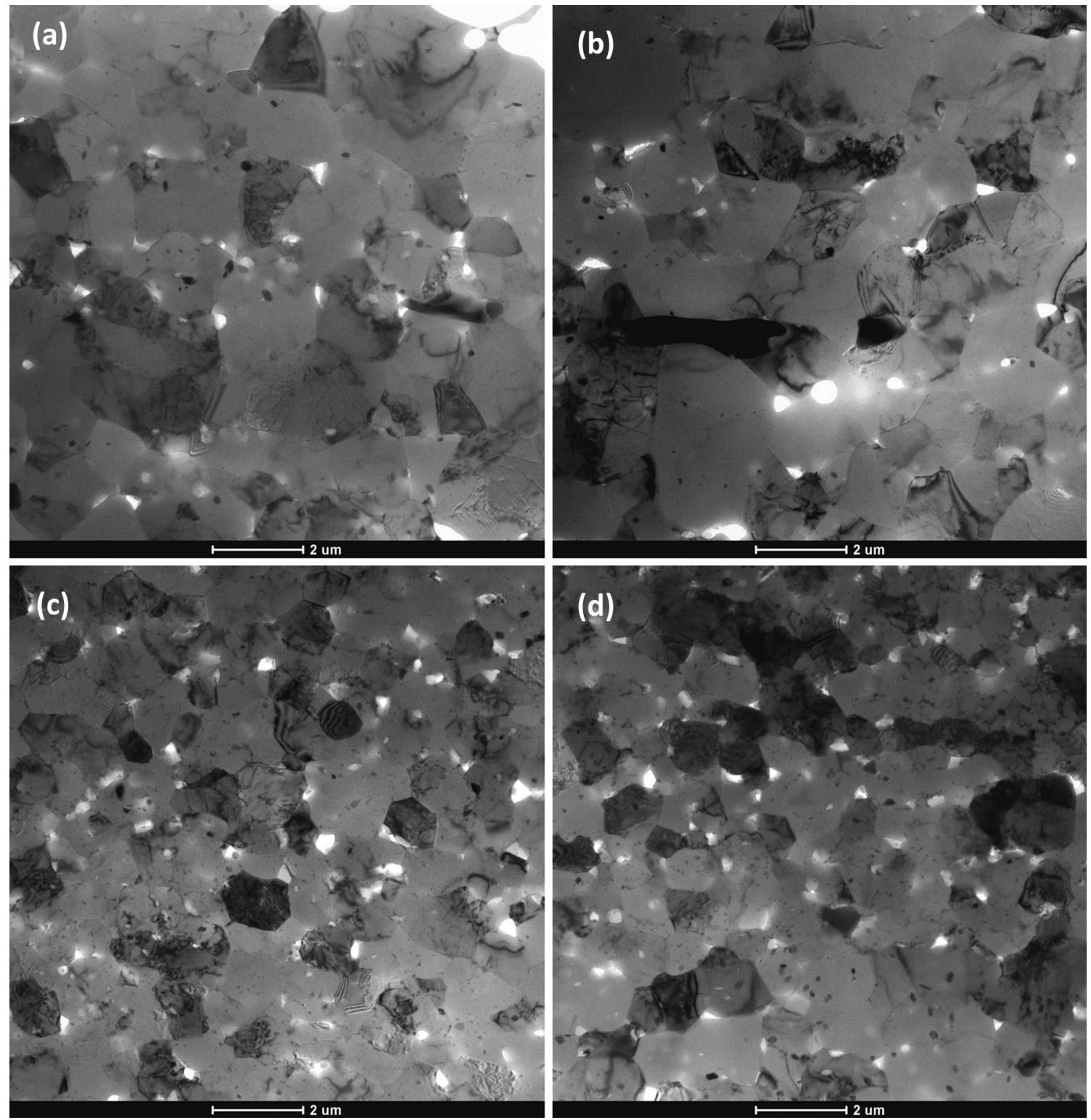

Fig. 4 TEM images of the 7075Al alloy under different atomization gas pressures: a $0.15 \mathrm{MPa}$; b $0.17 \mathrm{MPa}$; $0.19 \mathrm{MPa}$; d $0.21 \mathrm{MPa}$ 


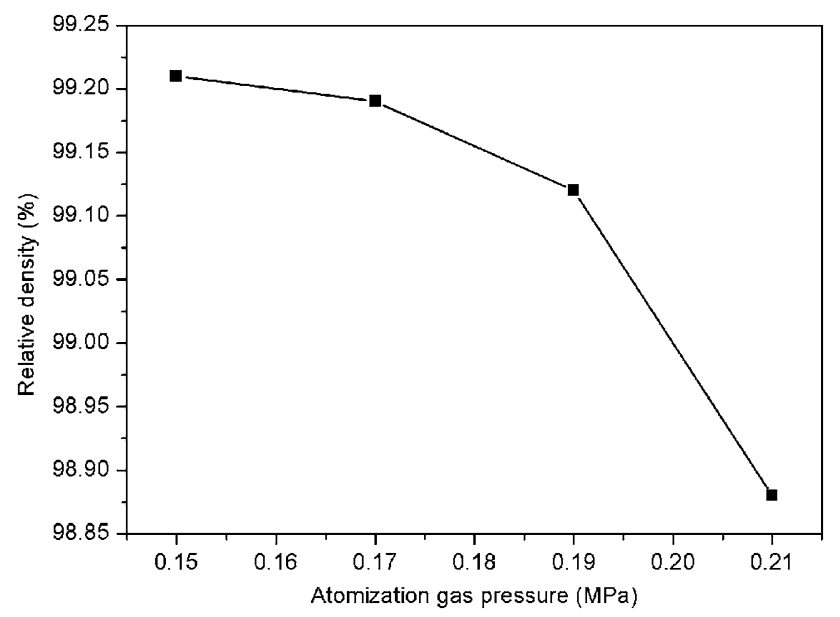

Fig. 5 Variations of the relative density of the 7075Al alloy with different gas pressures

procedure of continuous extrusion, the intense internal shear band and relatively high temperature exist in the deformation zone. The intense internal shear band reduces the unevenness of plastic deformation [34] and contributes to the plastic deformation of the alloy. At the stage of temperature rising, the accumulation of dislocations leads to dramatic deformation stored energy, which will then accelerate dynamic recovery and even dynamic recrystallization [33]. The high temperature of raw materials during the whole manufacturing procedure provides a favorable condition to meet the requirements for precipitation.

Another obvious phenomenon in Fig. 4 is that the porosities existing in the as-deposited materials as shown in Fig. 2 are almost eliminated. The relative density of the processed alloy is shown in Fig. 5, indicating that the relative density decreases with the increase of atomization gas pressures. This is because more porosities exist in the preform sprayed at a higher atomization gas pressure (Fig. 3). The present extrusion force formed in the extrusion cavity cannot completely eliminate the numerous porosities. Thus, it is imperative to use larger extrusion ratio to eliminate the porosities and to improve the relative density of the extruded products eventually [35]. Only increasing the relative density can makes the mechanical properties be enhanced.

\subsection{Microstructure and Properties of the RRA 7075Al Alloy}

Figure 6 shows the initial microstructures of the transverse section of the 7075Al alloy, which was firstly fabricated by directly combined of the spray forming and Conform under spraying pressures of 0.17 and $0.19 \mathrm{MPa}$, respectively, and then processed with RRA treatment. Compared with the materials that were not processed with RRA treatment, the both RRA samples exhibited pretty grains with diameters excess about $5 \mu \mathrm{m}$. And some large precipitates can be found in the junction of the grain boundaries. This is helpful to further improve the mechanical properties.

Moreover, the more detailed TEM analysis was performed on the RRA 7075Al alloy, as shown in Fig. 7. Many fine precipitates, with about $20 \mathrm{~nm}$ in size, uniformly distribute in the matrix. They are equiaxed-, triangular-, and rod-shaped. According to Orowan mechanism, the strengthening depends not only on the particle size distribution, but also on the uniformity of the dispersion [36].
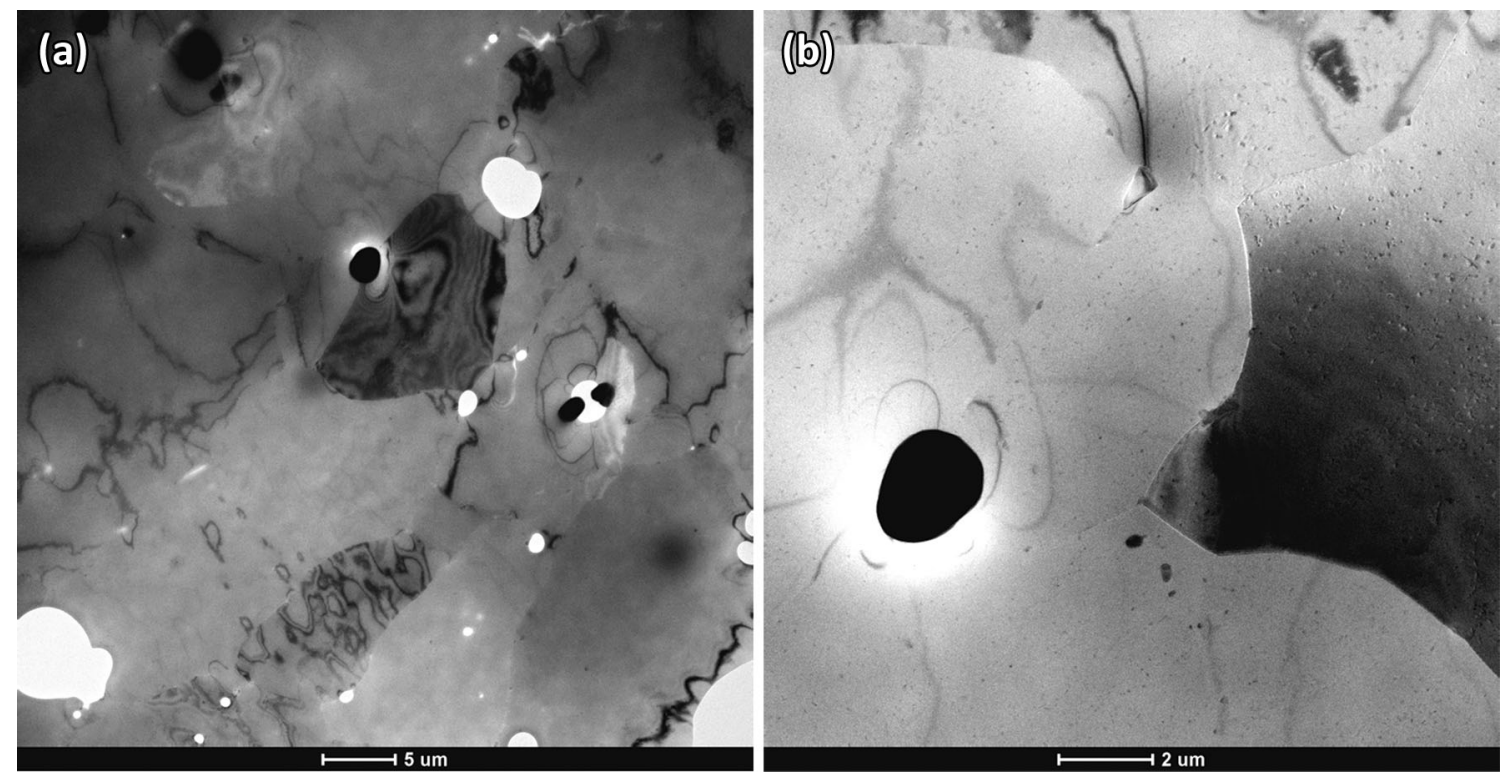

Fig. 6 TEM images of the RRA 7075Al alloy under different atomization gas pressures: a $0.17 \mathrm{MPa}$; b $0.19 \mathrm{MPa}$ 


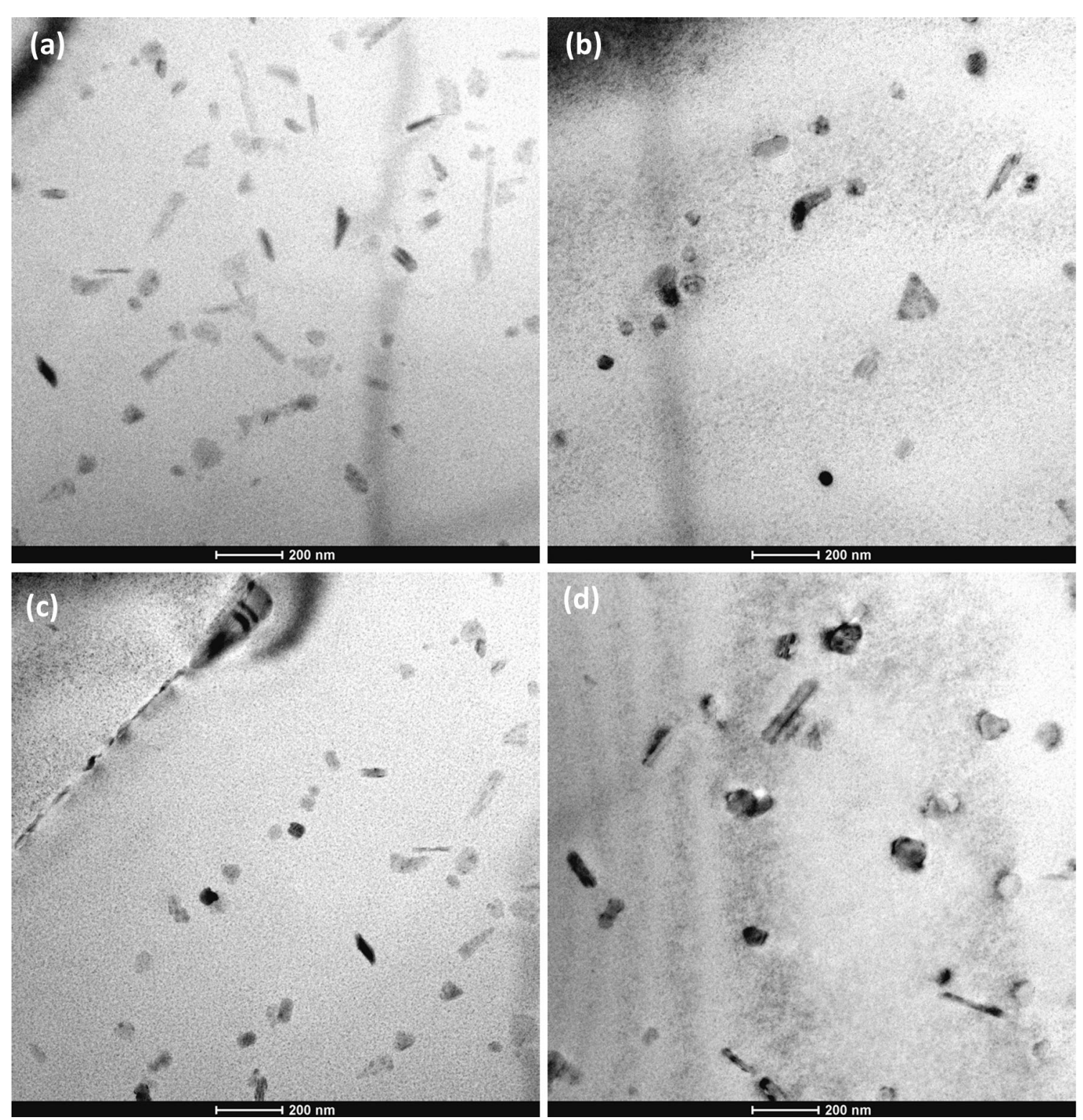

Fig. 7 TEM images of the RRA $7075 \mathrm{Al}$ alloy under different atomization gas pressures: a $0.15 \mathrm{MPa}$; b $0.17 \mathrm{MPa}$; $0.19 \mathrm{MPa}$; d $0.21 \mathrm{MPa}$

The particles are similar in size and distribute homogeneously and thus produce superior mechanical performance.

From Fig. 7c, it is evident that nanoscale precipitates discontinuously distribute not only at the grain boundaries, but also within the grains. And the grain boundaries present discontinuity after RRA heat treatment $[37,38]$. The discontinuous morphology plays a significant role in increasing stress corrosion cracking resistance without decreasing the strength $[8,33,39]$.

The XRD patterns of the RRA alloys are shown in Fig. 8. The precipitation of $\mathrm{AlCu}$ and $\mathrm{MgZn}_{2}$ phases is observed in four different atomization conditions. The intensity of the second-phase peaks shows little difference, which indicates the RRA process characterization. The difference in the intensity of $\mathrm{Al}$ peaks $\left(2 \theta=65^{\circ}\right)$ may blame to the change of the crystal orientation distributions during the process [40].

A relationship between electrical conductivity and stress corrosion cracking resistance of the $\mathrm{Al}-\mathrm{Zn}-\mathrm{Mg}$ alloys has been established [41]. Electric conductivity of the RRA $7075 \mathrm{Al}$ alloy is presented in Fig. 9. It is obvious that the value of the electric conductivity reaches the maximum value of $24.88 \mathrm{MS} \mathrm{m}^{-1}$ under the atomization gas pressure of $0.19 \mathrm{MPa}$ [42]. According to the relative densities shown in Fig. 5, the value of the electrical conductivity decreases sharply at $0.21 \mathrm{MPa}$ due to the great amount of the mass interstitial porosity existing in the matrix. But, the 


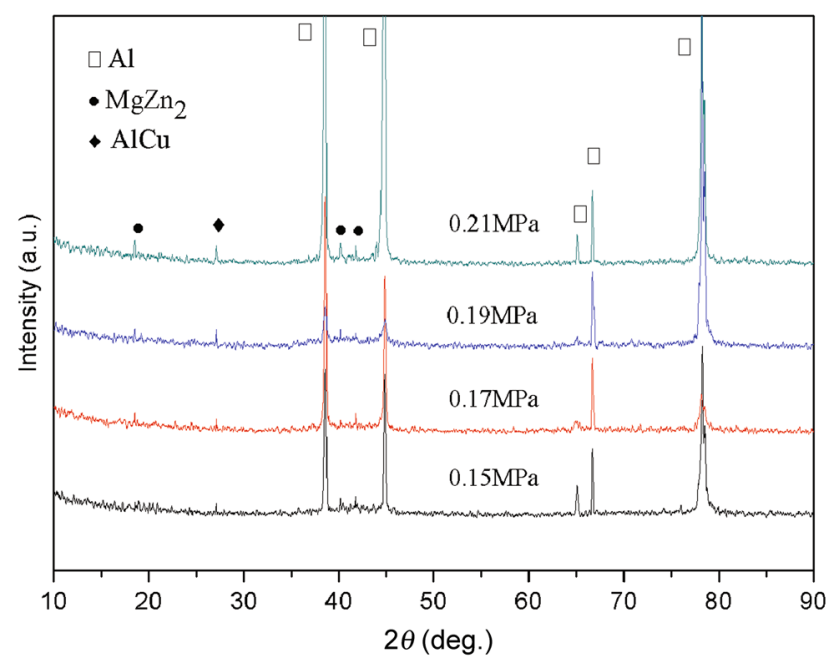

Fig. 8 XRD patterns of the RRA 7075Al alloy with different atomization gas pressures

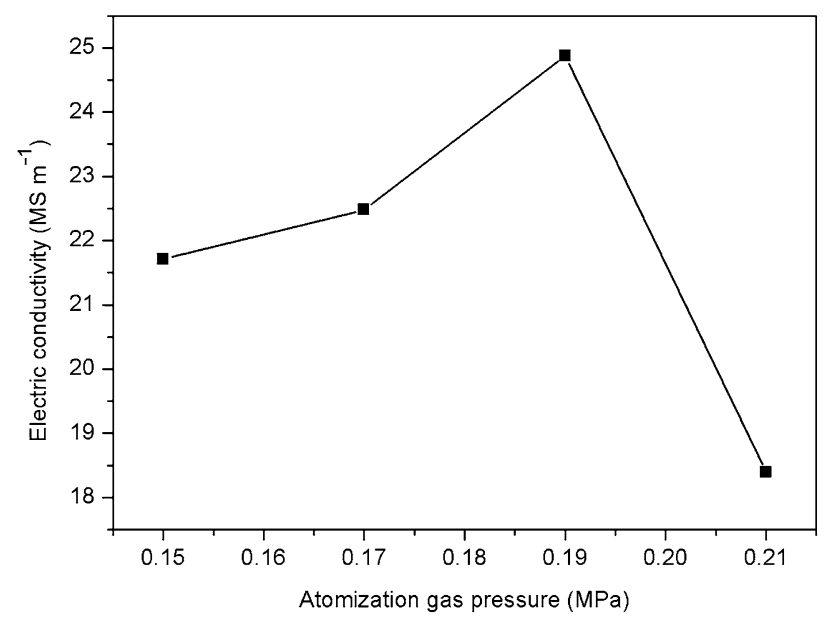

Fig. 9 Variations of the electrical conductivities of the RRA 7075Al alloy under different atomization gas pressures

electrical conductivities of 0.15 and $0.17 \mathrm{MPa}$ are lower than that of $0.19 \mathrm{MPa}$, which is probably due to the existence of the micro-segregation, gas porosity and solidification shrinkage. Therefore, it is predicted that the RRA prepared alloy would thus provide a superior stress corrosion cracking resistance through the control of the atomization gas pressure.

The accurate engineering stress-strain curves of the RRA 7075Al alloy are shown in Fig. 10. The yield strength and ductility obtained from the four samples fabricated in four different atomization conditions largely meet the aeronautical standard AMS $4050 \mathrm{H}$ for this material [33]. The ultra-tensile strength of all the samples exceeds $500 \mathrm{MPa}$, and the maximum strength is $547 \mathrm{MPa}$. It is worthy to note that the elongation of the sample sprayed at $0.19 \mathrm{MPa}$ reaches $19 \%$, and at the meanwhile, the

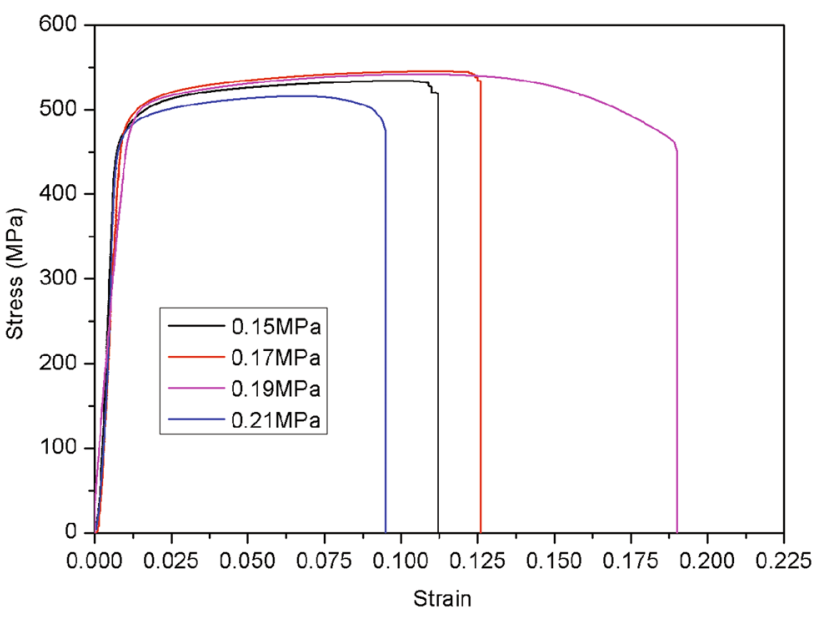

Fig. 10 Engineering stress-strain curves of the RRA 7075Al alloy at different gas pressures

mechanical strength, $541 \mathrm{MPa}$, does not decline dramatically.

The significant differences of the mechanical strength are closely related to the different atomization gas pressures, which would then result in the differences of the solid fraction in the droplets during the flight procedure and the structures of the deposited materials [43]. When the atomization gas pressure is low, such as 0.15 or $0.17 \mathrm{MPa}$, the liquid fraction will be high in the droplets and the deposited preform, as a result leading to the severe microsegregation even macro-segregation. Nevertheless, it is difficult to completely eliminate the heterogeneous microstructure by the follow-up heat treatment process, leading to the deterioration in the mechanical properties. When the atomization gas pressure is high, such as $0.21 \mathrm{MPa}$, the solid fraction will be high in the droplets and thus leads to numerous porosities in the matrix during preforming. It is also difficult to completely eliminate the porosity by the follow-up extrusion process. Therefore, the mechanical performance will be weakened. This phenomenon of low density of the spray preform directly leads to the low density of the products, as shown in Fig. 5 . Hence, excellent mechanical properties do not likely to be achieved under too high or too low atomization gas pressures.

Figure 11 presents fracture micrographs of the RRA 7075 samples. The fractured surfaces of all the samples are covered with the dimples, indicating that the micromechanism of fracture is void nucleation, growth and coalescence. However, these dimples exhibit different morphology characteristics under different atomization gas pressures. A positive conclusion can be obtained that the fracture dimples display more homogeneous and deeper when the RRA sample is prepared at atomization gas pressure of $0.19 \mathrm{MPa}$ (Fig. 11c). Therefore, it indicates 

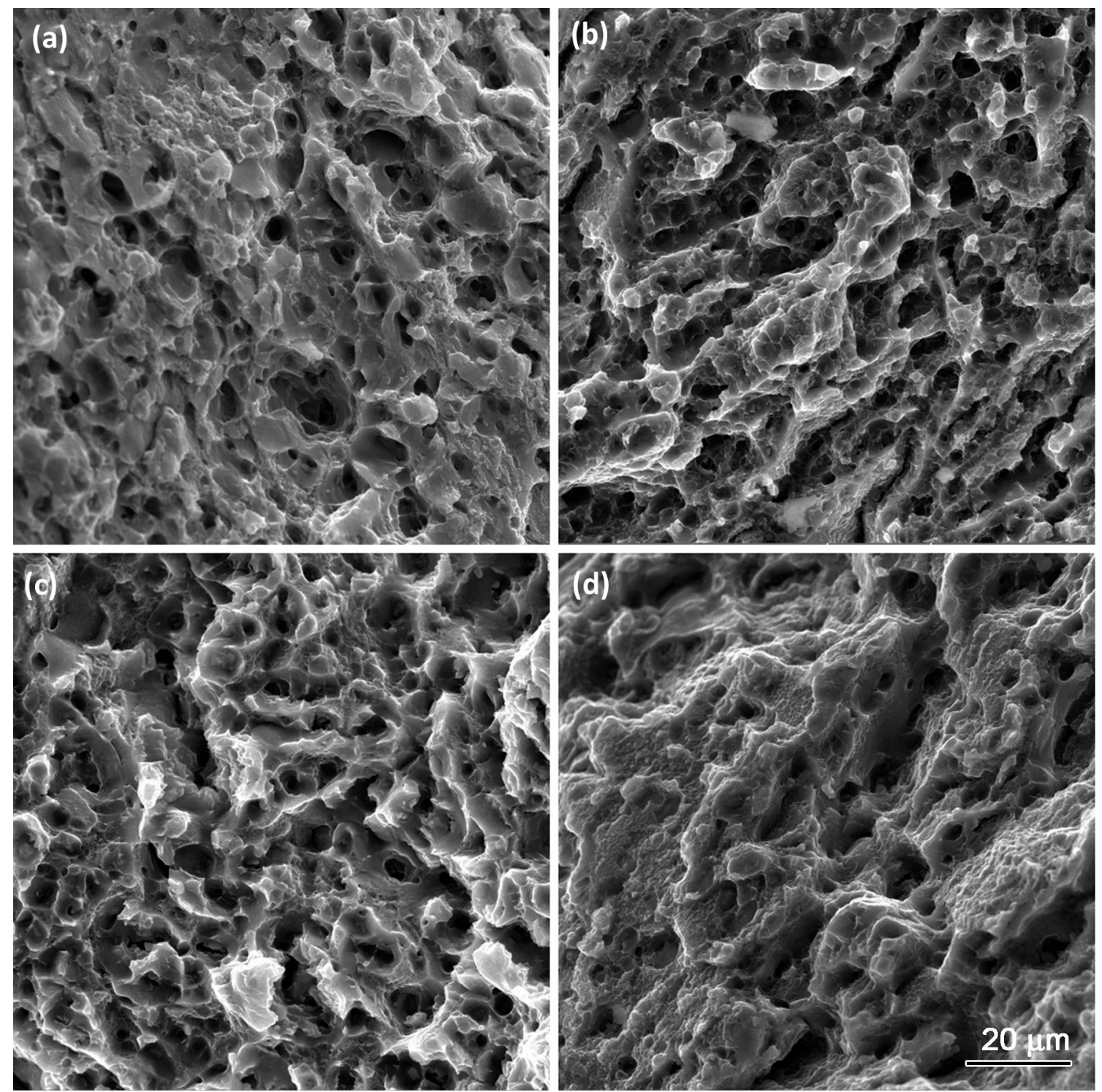

Fig. 11 SEM fracture micrographs of the RRA 7075Al alloy under different atomization gas pressures: a $0.15 \mathrm{MPa}$; b $0.17 \mathrm{MPa}$; $0.19 \mathrm{MPa}$; d $0.21 \mathrm{MPa}$

that an improved microstructure homogenization process could be obtained during the whole process, especially at the stage of atomization [44]. In addition, the high packing density couples with the low porosity obtained in the processed samples account for the above phenomenon. The morphology analysis of the dimples can exactly show the ductility of the specimen studied, which is corresponding to the result of the tensile tests (Fig. 10).

\section{Conclusions}

1. The processed $7075 \mathrm{Al}$ alloy has a better combined mechanical properties and a higher resistance to stress corrosion cracking when the atomization gas pressure is $0.19 \mathrm{MPa}$. Generally, tensile strength of $541 \mathrm{MPa}$, elongation of $19 \%$ and electrical conductivity of 24.88 $\mathrm{MS} \mathrm{m}^{-1}$ were obtained after retrogression and reaging (ASR) heat treatment.

2. The process of directly combined of the spray forming and the continuous extrusion forming can effectively refine grains and precipitates and improve the uniformity of the microstructure, which can conduce to the improvement of the mechanical performance. The sizes of the refined grains and precipitates can reach $1 \mu \mathrm{m}$ and $20 \mathrm{~nm}$, respectively.

3. The enhanced properties are associated with the fine and homogeneous distribution of $\mathrm{MgZn}_{2}$ and $\mathrm{AlCu}$ 
precipitates, the grain refinement, the high density of the products, as well as the discontinuous distribution of the grain boundaries after RRA heat treatment.

Acknowledgments This work was supported by the National Natural Science Foundation (508740655) and Yunnan Province Natural Science Foundation (2007E0013Z).

\section{References}

[1] Q. Wei, B.Q. Xiong, Y.A. Zhang, B.H. Zhu, L.K. Shi, Trans. Nonferr. Met. Soc. China 11, 258 (2001)

[2] P. Bai, X. Hou, X. Zhang, C. Zhao, Y. Xing, Mater. Sci. Eng., A 508, 23 (2009)

[3] J.T. Burns, J.M. Larsen, R.P. Gangloff, Int. J. Fatigue 42, 104 (2012)

[4] M. Chemingui, G. Mesmacque, A.W. Kolsi, Phys. Proc. 2, 1167 (2009)

[5] X. Fan, D. Jiang, Q. Meng, L. Zhong, Mater. Lett. 60, 1475 (2006)

[6] T.R. Prabhu, Acta Metall. Sin. (Engl. Lett.) 28, 909 (2015)

[7] X.M. Li, M.J. Starink, J. Alloys Compd. 509, 471 (2011)

[8] F. Wang, B.Q. Xiong, Y.A. Zhang, B.H. Zhu, H.W. Liu, X.Q. He, Chin. J. Nonferr. Met. 17, 1058 (2007)

[9] S.H. Wang, L.G. Meng, S.J. Yang, C.F. Fang, H. Hao, S.L. Dai, X.G. Zhang, Trans. Nonferr. Met. Soc. China 21, 1449 (2011)

[10] Y.P. Xiao, Q.L. Pan, W.B. Li, X.Y. Liu, Y.B. He, Mater. Des. 32, 2149 (2011)

[11] X.B. Yang, J.Z. Liu, J.H. Chen, C.Y. Wan, L. Fang, P. Liu, C.L. Wu, Acta Metall. Sin. (Engl. Lett.) 27, 1070 (2014)

[12] A.R.E. Singer, Met. Mater. 4, 246 (1970)

[13] A. Lawley, Melt atomization and spray deposition, Proceedings of the international conference on spray deposition and melt atomization (University of Bremen, Bremen, 2000), p. 3

[14] A. Leatham, Mater. World 4, 317 (1996)

[15] C. Cui, A. Schulz, K. Schimanski, H.W. Zoch, J. Mater. Process. Technol. 209, 5220 (2009)

[16] N. Raghukiran, R. Kumar, Mater. Sci. Eng., A 641, 138 (2015)

[17] L. Achelis, V. Uhlenwinkel, R. Ristau, P. Krug, Materialwiss. Werkstofftech. 41, 498 (2010)

[18] B. Cantor, K.H. Baik, P.S. Grant, Prog. Mater Sci. 42, 373 (1997)

[19] H.A. Godinho, A.L.R. Beletati, E.J. Giordano, C. Bolfarini, J. Alloys Compd. 586, 139 (2014)
[20] M.M. Sharma, M.F. Amateau, T.J. Eden, Acta Mater. 53, 2919 (2005)

[21] F. Wang, B.Q. Xiong, Y.G. Zhang, H.W. Liu, Z.H. Li, Q. Liu, Mater. Sci. Eng., A 518, 144 (2009)

[22] J.X. Xie, Advanced Processing Technology of Materials (Metallurgical Industry Press, Beijing, 2006), p. 197. (in Chinese)

[23] X.Y. Zhang, H. Zhang, X.X. Kong, D.F. Fu, Trans. Nonferr. Met. Soc. China 25, 1763 (2015)

[24] R.G. Guan, Z.Y. Zhao, R.Z. Chao, C. Lian, J.L. Wen, Trans. Nonferr. Met. Soc. China 22, 1182 (2012)

[25] L. Guo, D.Q. Yi, B. Zhang, B. Wang, H.Q. Liu, G.Q. Liu, Chin. J. Nonferr. Met. 23, 2083 (2013)

[26] Y.F. Wang, J.C. Yin, D.L. Zheng, Y.L. Liu, Y. Zhong, J. Mater. Sci. Eng. 32, 380 (2014)

[27] C.W. Wang, J.C. Yin, J.B. Zhou, Y.L. Liu, P. Gao, M.H. Li, Y. Zhong, Chin. J. Nonferr. Met. 23, 957 (2013)

[28] G.F. Liang, P. Gao, J.B. Zhou, Y. Zhong, Hot Working Tech. 40, 177 (2011)

[29] P.S. Grant, W.T. Kim, B. Cantor, Mater. Sci. Eng., A 134, 111 (1991)

[30] Q. Xu, E.J. Lavernia, Scr. Mater. 41, 535 (1999)

[31] C. Meyer, N. Ellendt, L. Mädler, H.R. Müller, F. Reimer, V. Uhlenwinkel, Materialwiss. Werkstofftech. 45, 642 (2014)

[32] B.L. Zheng, Y.J. Lin, Y.Z. Zhou, E.J. Lavernia, Metall. Mater. Trans. B 40, 768 (2009)

[33] Y.G. Chen, Y. Zhong, J.C. Yin, L.Q. Wang, H. Yang, L.N. Liu, Y.L. Liu, RSC Adv. 5, 97612 (2015)

[34] Y.D. Jia, F.Y. Cao, S. Guo, P. Ma, J.S. Liu, J.F. Sun, Mater. Des. 53, 79 (2014)

[35] H. Li, The Research on the Microstructure and Properties of the Al-20Si Alloy Prepared by Directly Combined of Spray Forming and Continuous Extrusion Forming, M.S. thesis, Kunming University of Science and Technology, 2015

[36] L. Kollo, C.R. Bradbury, R. Veinthal, C. Jäggi, E. CarreñoMorelli, M. Leparoux, Mater. Sci. Eng., A 528, 6606 (2011)

[37] R.M. Su, Y.D. Qu, R.D. Li, Q.M. Xie, J.H. You, Chin. J. Nonferr. Met. 24, 659 (2014)

[38] K. Ural, J. Mater. Sci. Lett. 13, 383 (1994)

[39] M. Talianker, B. Cina, Metall. Trans. A 20, 2087 (1989)

[40] X. Kong, H. Zhang, X. Ji, Mater. Sci. Eng., A 612, 131 (2014)

[41] T.C. Tsai, T.H. Chuang, Corrosion 52, 414 (1996)

[42] R.M. Su, Y.D. Qu, R.D. Li, Acta Metall. Sin. 50, 863 (2014). (in Chinese)

[43] W. Cai, E.J. Lavernia, Metall. Mater. Trans. B 29, 1085 (1998)

[44] X. Ji, H. Zhang, S. Luo, F. Jiang, D. Fu, Mater. Sci. Eng., A 649, 128 (2016) 